\title{
Research on the Application of Financial and Taxation Big Data in Enterprise Taxation Risk Management
}

\author{
Zhang $\operatorname{Min}^{1}$ \\ ${ }^{1}$ Dalian Vocational \& Technology College, Zip code: 116033 , Theory and practice of finance and taxation, Dalian, Liaoning
}

\begin{abstract}
At present, it is an important period for the comprehensive deepening of China's economic system. Enterprises will generate a large amount of fiscal and taxation data in production. Traditional financial management methods no longer meet the needs of current social development. It is necessary to integrate big data and Internet of Things technology to make it clear and establish an effective risk assessment mechanism to ensure the stable development. The article will mainly discuss the application research of fiscal and taxation big data in enterprises taxation risk management.
\end{abstract}

\section{Introduction}

In the era of big data, the taxation risks of enterprises are also increasing exponentially. Financial management personnel should be based on the needs of the times, clarify the financial and taxation risks in the production, innovate internal financial and taxation data management models, and establish data analysis. It can help enterprises effectively avoid taxation risks, improve internal risk mechanisms, and ensure long-term and stable development.

\section{An overview of fiscal and taxation big data and taxation risk management}

Financial and taxation big data mainly includes taxation, invoice, finance, tripartite and others. Big data refers to a collection that cannot be captured and processed in a short time. It is a representative of information assets and diversification, complexity with relatively low value content. The advent of the era of big data provides enterprises with new opportunities. Enterprises must continue to optimize calculations, meet the diverse needs of users in integrity verification, archive and prevent webpages from being tampered with. It can also break through the limitations of time and space and realize a new modern management model.

Tax risk management system mainly includes single strategy, tax planning, comprehensive strategy, tax assessment strategy, etc. Tax risk management is an important part of the production and development of an enterprise. Financial personnel should coordinate various data, and improve the quality of internal risk management based on the database. The era of big data has followed one after another, which has injected the driving force for enterprises. There is a certain degree of subjectivity in the decision-making of traditional enterprises. Managers should clarify the importance of fiscal and taxation data and improve the internal information protection mechanism, clarify positioning and strengthen subsequent risk estimation.

\section{The significance of financial and taxation big data and taxation risk management}

\subsection{Improve daily work efficiency}

The traditional taxation risk management model is relatively simple, and manual calculation is still used, which affects the final management. In the new situation, the combination of big taxation data and internal risk control mechanisms can effectively manage through a data-based management system, and timely check the risks in the production with a sound financial system. Through data analysis, it can show the market outside, reasonably avoid risks, and lay the foundation.

\subsection{Integrate multiple data resources}

Risk management is complex and long-term. Enterprises need to coordinate multiple resources and import daily taxation and financial data into the risk system. Based on the production status of enterprises, it can couple multiple indicators, establish the corresponding risk model, understand the taxation status with a sound risk rating evaluation system, and realize effective overall management.

\subsection{Improve the internal management model}

Enterprise taxation risk management can reduce the 
pressure of financial personnel, improve the quality of management, truly link outbound, inbound, circulation, and sales, and make effective adjustments to minimize taxation to achieve the overall goal. It can help enterprises save expenses, avoid taxes reasonably, raise additional funds and improve the daily financial management system, form monthly and quarterly reports, start with the flow of funds, and establish a ledger mechanism.

\section{Problems existing in the application of fiscal and taxation big data}

Fiscal and taxation risk management is inevitable in the daily development of enterprises. Managers should give full play to the advantages of fiscal and taxation big data. In the actual process, there are still many problems to be solved.

\subsection{Backward taxation risk concept}

Most enterprises only pay attention to short-term economic benefits, and fail to realize the long-term impact of taxation on enterprises. Financial personnel don't study and understand the core concepts of risk management, which will cause a lot of waste of resources and is not conducive to the long-term stable development.

\subsection{Lack of integrated use of data from the fiscal and taxation resource database}

Enterprises will generate a lot of redundant data in taxation management. The big data of fiscal and taxation internally covers a series of data in enterprises. Managers lack the mining and reuse of information, and the value of information density is low. In addition, the problem of information asymmetry is more prominent with a lack of effective taxation risk management and control models. The authenticity cannot be guaranteed, and effective evaluation and management of external risks cannot be achieved.

\subsection{Low safety factor}

Fiscal and taxation big data contains a large amount of core data in the enterprise. But in the actual management, the safety factor is low, and data disclosure problems may arise. The follow-up of fiscal and taxation big data needs to invest a lot of manpower and material resources for data management. In addition, taxation risk management does not have a specific filing. Various departments have overlapping powers with a long turnaround time. The fund management and issuance is complicated. There is a mismatch between funds and deposits and debts, which has increased the the amount of financial personnel work.

\section{Application research of big data of finance and taxation in risk management}

Fiscal and taxation big data in the management is an important part and a need as a whole financial personnel strength. It can improve the coupling of internal system, give full play to the big data advantage, improve the internal risk control system, follow-up development to provide effective data base, break the traditional management mode, and improve enterprise internal risk management ability.

\subsection{Improve the data integration pattern}

Financial management personnel should improve the internal risk control mechanism, establish a sound data application rules, and improve the overall quality of taxation risk management. Strictly abide by taxation law and guarantee the fiscal and taxation data scientific and integrated development, comprehensive utilization of cloud network, strengthen the pro-phase data acquisition mechanism, perfect the internal data sharing mechanism with a unified data format, reduce the working pressure of personnel, clear tax-related information inner coupling relationship to ensure that information is highly unified. It needs to apply financial big data technology to enterprise risk management, establish data-based thinking, and make full use of the dividend of data technology. The existing problems in tax administration should be clarified, and the traditional extensive mode should be changed, and the analysis and mining of data should be emphasized.

For example, a combination analysis of target sources should be carried out by means of mathematical formulas. The upper and lower limits shall be set directly, and the warning shall be carried out in the way of risk early. Finally, the analysis model shall be created to provide support for the subsequent risk analysis through the databased management and control method. Reverse thinking is adopted to carry out recovery management, emphasizing data collection at the bottom level and risk scanning in key areas. After identification, risk levels should be classified, and risk monitoring and subsequent feedback evaluation mechanism should be done. It needs to fully implement the fiscal and taxation big data system, realize intelligent storage, analysis, query, etc., ensure that tax software can be compatible with win 10 , Win7, IOS and other office systems at the same time, and further improve the efficiency of planning from a comprehensive perspective to analyze, provide targeted measures.

\subsection{Establish a taxation risk control system}

In the process of establishing the risk control system, enterprises should start with the original certificate to determine the taxpayer's application form, financial statements and so on. Secondly, according to the indicator, it needs to create various elements of comprehensive sales revenue, tax payable, tax receipts and other resources. In the process of indicator source element analysis, it is also necessary to comprehensively consider the individual characteristics of the enterprise, constantly combine with multiple historical data, fully analyze various risks, and formulate an effective risk control mechanism.

For example, in the process of tax management, one should understand the tax differences of different 
industries, combine current hot issues, analyze historical data, and choose tax-preferential industries for investment, continue to pay attention to the development of high-tech industries, make decentralized investments, and integrate intangibles and fixed asset investment to reduce taxes and save costs.

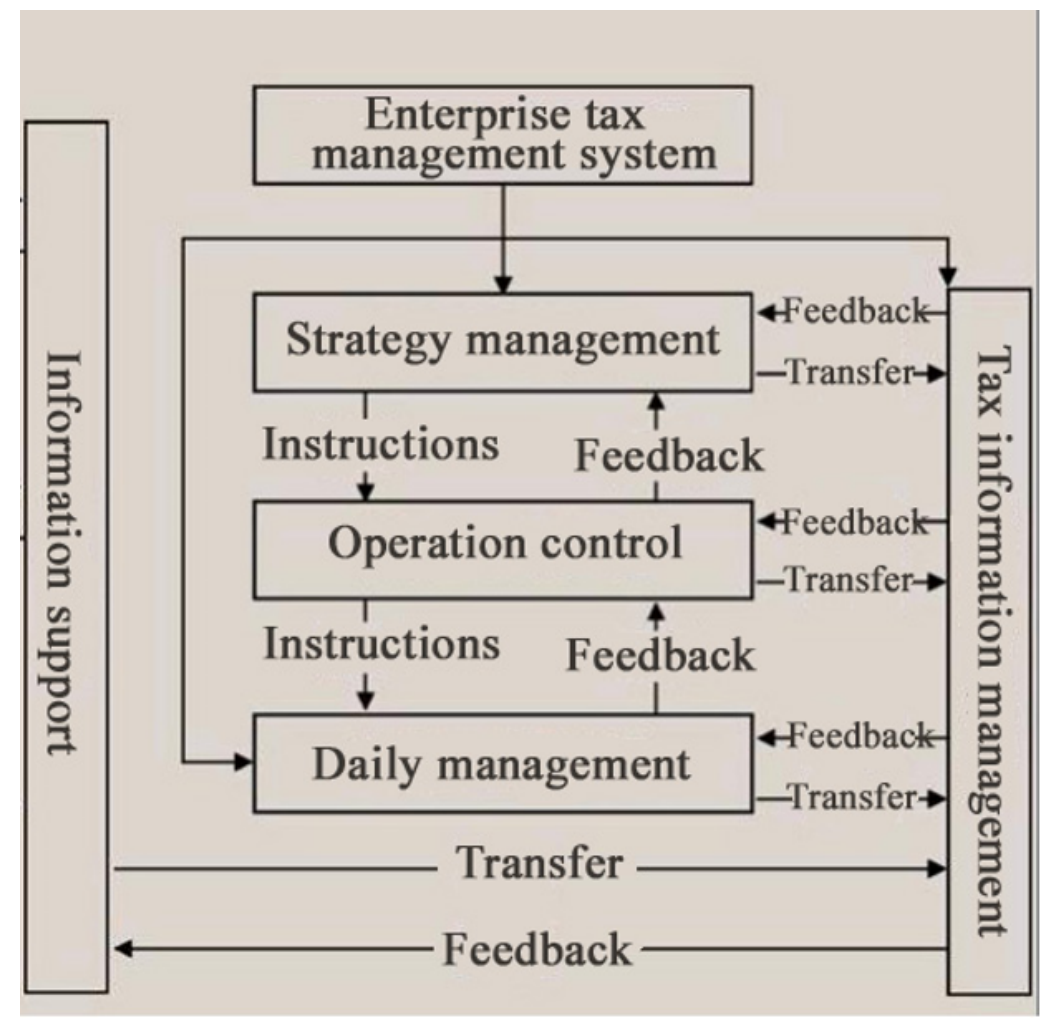

Fig1. The risk control system of fiscal and taxation big data

\subsection{Strengthen the data flow mechanism}

Enterprise taxation risk assessment is centered on the tax bureau. It analyzes various indexes of the enterprise's tax return data and identifies internal risk points.

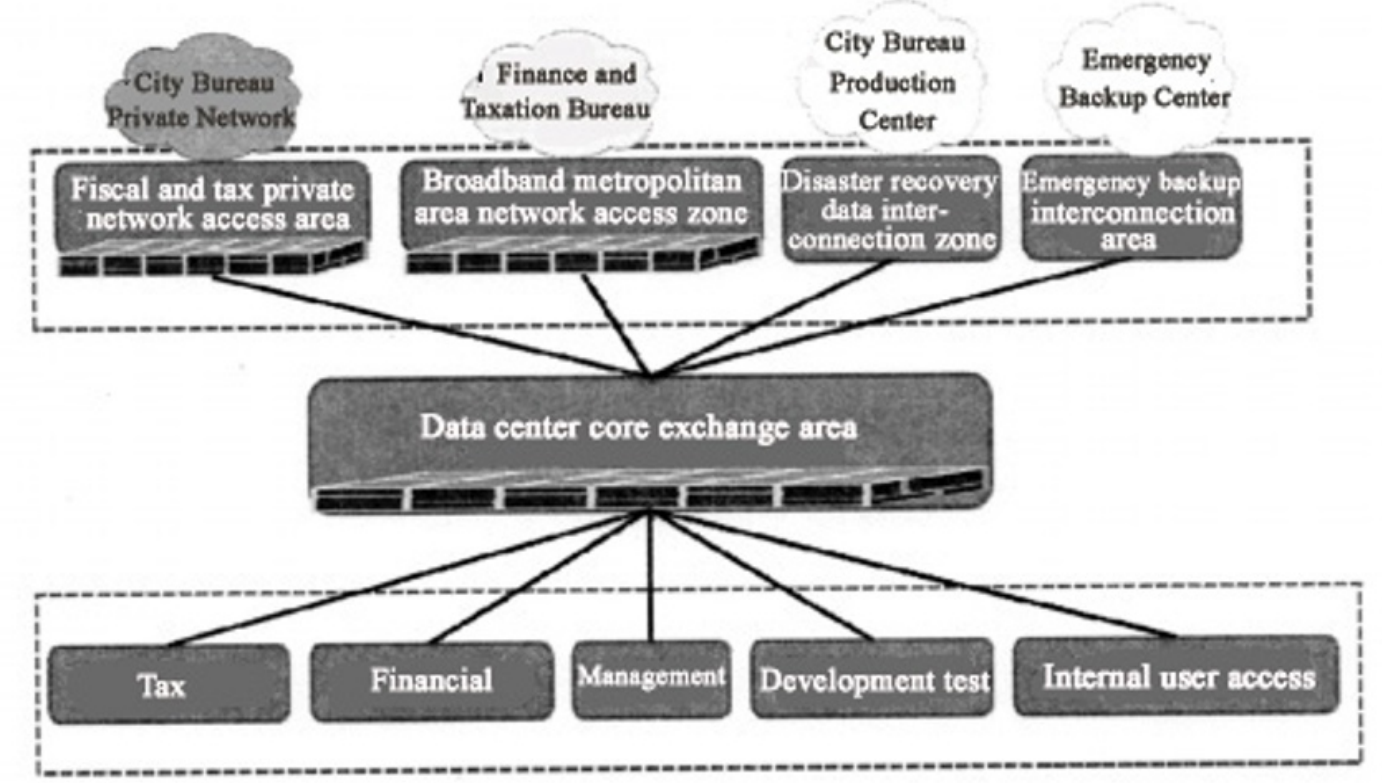

Fig2. The exchange model of fiscal and taxation big data

Through tax risk management, enterprises can evaluate their own tax risks to achieve the purpose of self- examination and avoidance. It can make clear the maintenance and stability requirements, form a holistic 
evaluation mechanism, start with the overall planning, make full use of the current information resources, reasonably deploy each link, further refine the demand, and complete the outline design. It can also form a detailed tax plan and data management mechanism, properly handle the relationship between production and tax, improve the internal operation and stability maintenance mechanism, make full use of various resources, improve the operating efficiency of the fiscal and taxation system to avoid risks.

Figure 2 The exchange model of fiscal and taxation big data

For example, enterprises can adopt the reverse diagnosis method of high duplication for consideration, think in other positions, simulate the role of the tax bureau, analyze internal risk indicators and specific models, and comprehensively analyze the indicator base of tax risk identification and model. The risks in the scanning are classified into high grade, middle grade and low grade. High risks should be directly reflected in the hands of enterprise managers and financial personnel, medium risks should be reflected in the hands of financial personnel, and low-risk areas need to establish an automatic early warning mechanism through adjustment mechanism. Taking data as the core partition and the center, it needs partition processing. The subsequent adjustment will be transformed into the supervision and management in advance, and the industrial chain serving the taxation will be extended to improve the ability to resist external changes.

\subsection{Strengthen the management mechanism of financial personnel}

As a relatively cumbersome task, financial risk management involves more content. Financial personnel have certain financial budgeting capabilities. At the same time, taxation policies are characterized by the times and dynamics. Financial personnel must constantly update their legal knowledge to deal with more complex external environments and establish a more complete operating system. To form a capital-oriented management mechanism to ensure the steady progress. The construction of the fiscal and taxation center must follow the principle of high reliability, coordinate a variety of hardware information, analyze the important losses caused by various business suspensions, and determine an effective backup mechanism and various business recovery indicators. In the overall construction of fiscal and taxation big data, in line with the principle of low-cost and high-efficiency construction, the daily backup test status is strengthened. Comprehensive database application and site and management expansion capabilities can strengthen daily risk management and control mechanisms.

For example, bonus shares or employee shareholding methods can be adopted to mobilize employees' production enthusiasm. In addition, enterprises can obtain funds through extensive fund raising, and use the funds obtained in production and operation through equity financing, debt financing, lease financing, etc. When choosing a funding method, it should be selected according to the current operating conditions. Pre-tax deduction for comprehensive issuance of stocks, enterprise debts, and financial institution settlements will ease the financial pressure on enterprises. At the same time, it should actively introduce external talents, and provide financial talents for enterprises by building a schoolenterprise cooperation platform and directional training of data talents. It ensures that the original top-down decisionmaking analysis mode is broken and a flat management mechanism is formed. Through data processing methods such as cloud platform and Internet of Things, an effective information integration management mechanism is formed by combining historical data to make decisionmaking scientific and objective.

\section{Conclusion}

The combination of big data of finance and taxation with enterprises taxation risk management can improve internal risk. Managers should also make it clear that there are problems in the application. Based on the actual situation of enterprises, they should improve the risk assessment mechanism, realize the whole control of capital, and provide effective data support for enterprise decisionmaking to ensure long-term and stable development.

\section{Acknowledgments}

Project supported by Dalian Vocational \& Technical College Scientific Research and Innovation Fund (No. DZ2019CXJJ02)

\section{References}

1. Xiao Yufeng. 2018. Analysis of the practice of big data in taxation risk management [J]. Taxation Research, (05): 123-127.

2. Ning Hongyi. 2020. Discussion on the application of financial and taxation big data in enterprise taxation risk management[J]. Accounting Study, (12):192, 194.

3. Chang Xiaosu. 2019. Analysis on the application of big data in taxation risk management $[\mathrm{J}]$. Taxation Research, (06): 78-81. 